\title{
INCREASED OIL PRODUCTION BY ADVANCED CONTROL OF RECEIVING FACILITIES
}

\author{
John-Morten Godhavn, Stig Strand and Gunleiv Skofteland
}

\author{
Statoil R\&D Process Control \\ Arkitekt Ebbells vei 10, Rotvoll, 7005 Trondheim, Norway \\ E-Mail:jimgo@statoil.com.Tel:+4790974301
}

\begin{abstract}
Slug flow from wells or multiphase flow lines from subsea satellite fields is one major disturbance at offshore oil and gas processing facilities. Slugging is an undesirable flow pattern with liquid blockages that can occur in multiphase flow lines transporting both gas and liquid. The original contribution in this paper is the successful application of advanced control for the inlet facilities, where active slug control for two $11.7 \mathrm{~km}$ long multiphase flow lines is combined with model predictive control to handle slugs entering the inlet separators. Copyright $(2) 2005$ IFAC

Keywords: Model Predictive Control, Slug Control, Flow Control, Level Control, Industrial Production Systems.
\end{abstract}

\section{INTRODUCTION}

Process control on offshore oil and gas production platforms is usually quite basic with a large number of single loop PID controllers taking care of levels, rates, pressures, temperatures, compressor and pump speeds, etc. Control theory is not considered among the most required fields of expertise, and offshore personnel are often not experts in control theory. The improvement potential of minor modifications, such as tuning parameters of these PID controllers, is therefore large in many cases. This is a contradiction to the economical benefits of improved control. A small increase in the production rate capacity or process regularity represents a lot of money.

In the land-based oil and gas industry advanced control is applied to a much greater extent. Especially Model Predictive Control (MPC) has found wide-spread. Statoil, for example, has many MPC applications running at their onshore refineries at Mongstad in Norway and Kalundborg in Denmark and at their gas processing plants Kårstø and Kollsnes in Norway.

This paper describes a control system that has increased the safety margins and the operation regularity at increased rates and reduced pipeline pressures for a tie-in of a subsea field to an oil and gas producing platform.

Slugging in the flow lines between the subsea field Tordis and the oil and gas production platform Gullfaks $\mathrm{C}$ has resulted in fluctuations in pressure and levels in the Tordis inlet separators, and variations in the gas- and liquid flows out of these. This causes problems for the operation of the inlet facilities. Slugging can be reduced by increasing the pipeline pressure. The limitation of this approach is that the increased pipeline pressure will reduce the production rate from Tordis in the tail end phase of the production lifetime.

The proposed control system has been installed on the receiving facilities for Tordis on Gullfaks C. The following methods have been applied:

1. Slug suppression by active slug control using the topside choke and a cascade controller of the topside volumetric rate and the pipeline inlet pressure.

2. Slug handling by advanced level control of the inlet separator using MPC to manipulate the level set points. 
The control system has solved the following tasks:

1. Stabilize the flow in the pipelines.

2. Reduce level and flow variations in the separators to prevent process shutdowns and reduce the number of level alarms.

In Section 2 the process is described. The control system is described in Section 3 and some results are given in Section 4.

\begin{tabular}{|l|l|}
\hline Short & Text \\
\hline CV & Controlled Variable \\
\hline DV & Disturbance Variable \\
\hline MPC & Model Predictive Control \\
\hline MV & Manipulated Variable \\
\hline OPC & OLE for Process Control \\
\hline PID & $\begin{array}{l}\text { Proportional, Integral and Derivative } \\
\text { controller }\end{array}$ \\
\hline RTO & Real Time Optimisation \\
\hline SEPTIC & $\begin{array}{l}\text { Statoil Estimation and Prediction Tool } \\
\text { for Identification and Control }\end{array}$ \\
\hline
\end{tabular}

Table 1. Abbreviations.

\section{PROCESS DESCRIPTION}

\subsection{The Tordis subsea field and the Gullfaks $C$ oil and gas production platform.}

The Tordis field operated by Statoil in the North Sea (Fig. 1) ranks as one of the most profitable Norwegian offshore developments. When production began in June 1994, recoverable reserves in this discovery were put at roughly 110 million barrels of oil. However, output so far is already more than double that figure. The Tordis East and Borg structures have been tied back to the original development, with total reserves upgraded to about 360 million barrels. Shut-down was originally scheduled for 2006, but it's set to continue producing for many more years. Production is still high, at almost 70,000 barrels/day (August 2004). A project is currently investigating the potential for increased oil recovery from Tordis by reducing the inlet pressure considerably. Operational regularity has been good with a current recovery factor of $49 \%$, and a target of exceeding $50 \%$ - very ambitious for a subsea development.

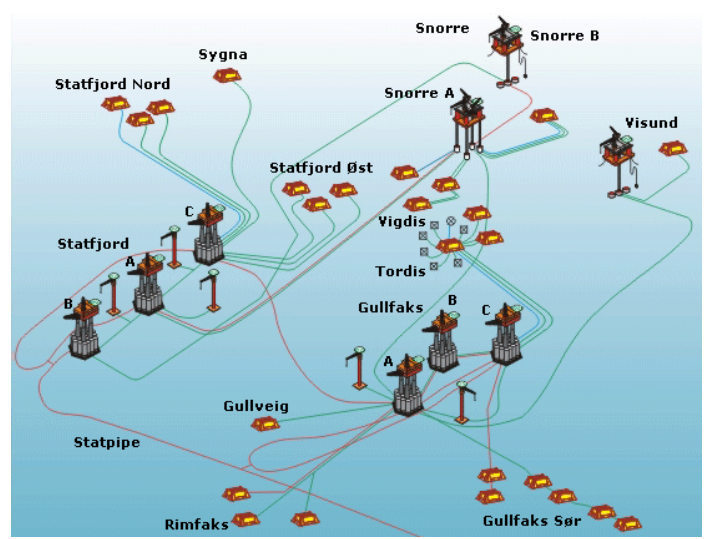

Fig. 1. The Tampen field including Tordis and Gullfaks C (Illustration Copyright (C) Statoil).

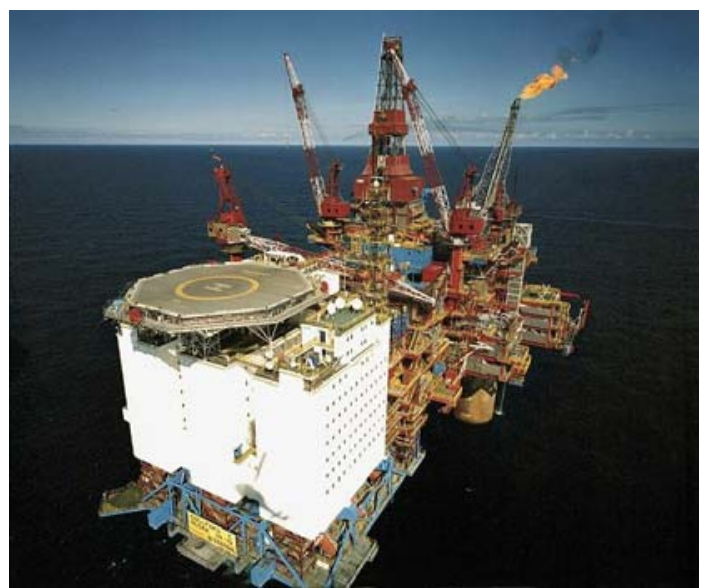

Fig. 2. Gullfaks C (Photo: Øyvind Hagen, Statoil).

Tordis has been developed with seabed installations tied back to Gullfaks C with two 10 inch $11.7 \mathrm{~km}$ long multiphase pipelines. Gullfaks C (Fig. 2) began production in November 1989. The total crude oil production at Gullfaks $\mathrm{C}$ is about 165.000 barrels/day.

The Tordis processing facilities at Gullfaks C consist of a one-step oil stabilizing system with two equal parallel oil trains, one for each pipeline. Each pipeline has two parallel production chokes and a three-phase separator for separation of gas, oil and water. Downstream the separators there are oil booster pumps, an oil metering station, a gas metering station and water cyclones. The Tordis oil is fed into the second step oil separator at Gullfaks C. Gullfaks C has two three-step oil stabilizing separator trains and two gas compression trains. Tordis gas is cooled in a gas cooler, dried in a gas scrubber and recompressed for either export via Statpipe to the Kårstø gas processing plant or reinjection into the reservoir for pressure support. The stabilized oil is stored in storage cells and collected with oil tankers.

\subsection{Multiphase Flow in the Tordis Pipelines}

Two field tests were conducted at Gullfaks C in 1998 and 1999 to measure slug flow in the Tordis lines. Slugs as long as 400 meters were measured with densitometers. Both tests showed that the slugging increased, when the pipeline pressure was reduced. A limit was therefore set on how low the pipeline pressure was allowed to be, in order to avoid severe topside processing problems due to slug flow in the pipeline. The motivation for the improved control project was to lower this pressure limit and make it possible to increase the production rate in the tail end of Tordis production. 

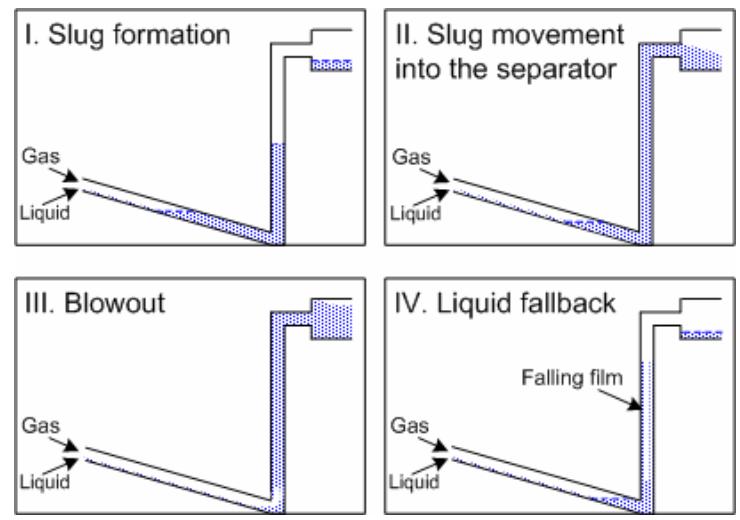

Fig. 3. The riser slug cycle.

Several types of slug flow have been observed in the Tordis pipelines. One type is transient slugging caused by changing process conditions. For example, a rapid increase in the topside choke opening will give a pipeline pressure drop and a rapid rate increase. This can introduce a transient slug. Start-up slugs are also considered in this category. A second type is hydrodynamic slugging that is formed way back in the pipeline. These are usually small and cause small problems for the topside processing. Field measurements indicate that there is a critical pressure/rate combination, where hydrodynamic slugs combine into the third and most severe type, riser slugging.

Riser slugs are formed at a low point in front of the riser, typically at the riser foot. A liquid blockage stops the gas from entering the riser. The liquid slugs grow until the upstream pressure is sufficiently high to push the slug up the riser (Fig. 3). In some cases some liquid falls back after a blow-out and forms a new slug in a cyclic way with severe variations in both rate and pressure.

Offshore density measurements from Gullfaks C show both hydrodynamic slugging (20-30 seconds period) and water slugging (3-15 minutes period). The water slugging takes place in the liquid phase (oil-water interface). It is terrain induced and cannot be recaptured with OLGA.

\subsection{Operational challenges from flow variations}

Variations in flow and pressure from the Tordis pipelines create several problems for the operation of the receiving facilities at Gullfaks C:

1. Oil (liquid) level variations can give a process shut down if the level gets higher or lower than the trip limits.

2. Large water (interface) level variations result in poor oil/water separation.

3. Oil flow variations out of the separator degrade the fiscal flow measurements.

4. Water flow variations reduce the performance of the hydro-cyclones.

5. Gas rate variations out of the separators introduce disturbances in the gas compression system.

\section{CONTROL SYSTEM}

The new advanced control system installed at Gullfaks C for Tordis is a combination of slug control and model predictive control.

\subsection{Slug Control.}

Background. The first known publications on slug control by feedback and active use of the topside choke are by Schmidt, et al. (1979a and 1979b), where terrain slugging was suppressed by using the topside choke and a feedback control loop using pressure measurements both at the inlet and upstream the riser during a series of experiments in a small scale loop. The results were followed up by Hedne and Linga (1990), who applied standard PIcontrol of the riser foot pressure in a medium scale experimental loop. Many groups have been working with this topic since then, and several systems are now in operation offshore. Shell has a patented slug control system S3 (Hollenberg et. al., 1995), where the multiphase flow is separated to gas and liquid in a mini separator. The gas flow and liquid flow out of the mini separator along with the mini separator level and pressure are controlled with separate gas and liquid valves. This method can suppress several kinds of slug flow. Total has a slug control system (Courbot, 1996 and Henriot et. al., 1999), where simulations predicted severe slugging and that the existing process equipment was too small to handle the slugs well. Design changes were too expensive, and a feedback control system was suggested and implemented. ABB (Havre et. al., 2000 and Havre and Dalsmo, 2001) has installed a product (Active Flowline Control) for active slug control at some oil and gas production platforms mainly in the North Sea, based on controlling the pipeline inlet pressure. These methods are effective towards riser slugging. Storkaas and Skogestad (2002 and 2003) have developed a simple model for the pressure-gravity dynamics of riser slugging. This low-dimensional model is well suited for control design and analysis. Analysis of this model has shown how and why slug control works. Riser slugging can be suppressed in several ways. Feedback control of the volumetric or mass flow through the topside choke is one possibility. A less conventional, but more robust method to suppress riser slugging, is to stabilize the pressure upstream the riser. The distance between the controller input (topside choke) and the output (inlet pressure) can then be very large.

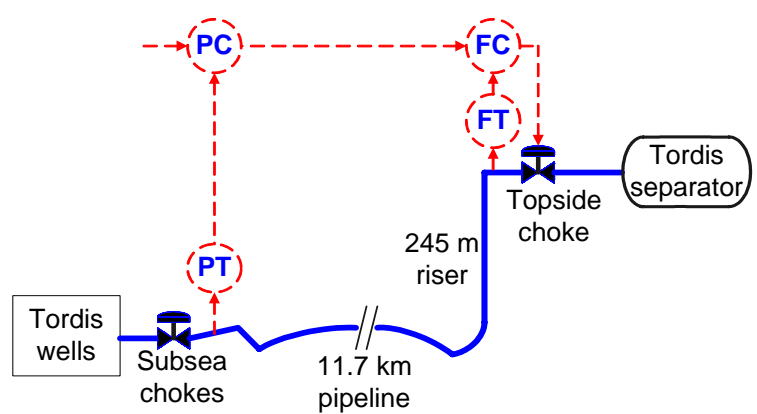

Fig. 4. Cascade control of inlet pressure and choke volumetric flow. 
Statoil has a large activity on multiphase flow and flow assurance and has, for example, been a very active partner in the development on the dominating multiphase flow simulator OLGA. Slug control in Statoil began with the early experiments of Hedne and Linga (1990), while the first slug control installation came at Heidrun TLP for the Heidrun Northern Flank D and E satellite fields in 2001 (Skofteland and Godhavn, 2003). A new cascade control structure (see Fig. 4) was developed for the Heidrun installation. This structure suppresses both riser slugging and more high frequent hydrodynamic and terrain slugging. Statoil ran slug control experiments at Sintef's medium scale loop in Trondheim to verify the properties of this cascade controller, both in 2001 and 2002. Results from the experiments in 2001 were presented in Skofteland and Godhavn (2003), while the results from 2002 are presented in Godhavn et. al. (2005) and Fard et. al. (2005).

Tordis slug control. These goals were defined for the slug control suppression system at Tordis:

1. Prevent severe slugging in the pipeline.

2. Avoid or minimize loss of production.

3. Stabilize pipeline inlet pressure to provide stable wellhead conditions.

4. Stabilize flow into Tordis separators to reduce separator level and pressure variations and reduce outlet flow variations.

These goals were achieved with the same cascade controller (Fig. 4) as was installed at Heidrun TLP in 2001 (Skofteland and Godhavn, 2003). A pressure controller in outer loop provides a set point to a slave flow controller. This flow controller uses the topside choke to get a desired volumetric flow through the choke. The volumetric flow is not measured directly, but computed from a simplified valve equation and measurements of density and choke pressure loss. Standard PID-controllers have been programmed in the topside process control system.

\subsection{MPC by SEPTIC}

Model predictive control in Statoil. In 1996 Statoil began the development of an in-house software system for MPC, Real Time Optimisation (RTO), simple dynamic process simulations and parameter estimation. Before then Statoil used commercial MPC products. The internal development was motivated by a desire to add new functionality, faster bug-fixes, and in general to be able to do a better job for the internal customer (Strand and Sagli, 2003). Statoil's MPC is called SEPTIC: Statoil Estimation and Prediction Tool for Identification and Control. The first SEPTIC installation came offshore on the Statfjord A oil and gas production platform in 1997 (Skofteland et. al., 1998). Statfjord A receives oil through an oil pipe from a neighbour oil production platform (Snorre A). Here the MPC is used to prepare the separators and compressors for a sudden decrease of production to avoid a cascade trip at Statfjord A, when Snorre A shuts down. A total of 53
(February 2005) SEPTIC applications are running in closed loop in Statoil. SEPTIC contains functionality for model predictive control using experimental step-response models. It has also possibilities of using nonlinear physical models (Strand and Sagli, 2003). SEPTIC can communicate with the process control systems in many ways, but for new applications it is advised to use the industry standard OPC.

An MPC has many possibilities. It can, for example, help the process adapt quickly to large production rate changes, maximize the capacity by improving the control, so that the safety margins can be reduced, better stay within process constraints as maximum and minimum level, reduce start-up time, improve regularity by better handling of large disturbances, and increase flexibility by having more and better controller parameters to adjust.

SEPTIC is normally used as a supervisory control system. A basic control layer is used to stabilize the system, while SEPTIC manipulates the set points of the basic controllers (see Fig. 5). Every MPC project in Statoil includes a phase where the basic PID controllers related to the MPC application are tuned. The success of an MPC application relies on operator participation. Operator courses are run both before and after the implementation to ensure operator belief and competence.

The Tordis SEPTIC applications for slug handling. The following goals were set for the Tordis A and B SEPTIC applications for slug handling:

1. Limit the level variations within given constraints

2. Minimize the oil rate variations into the Tordis oil metering station (achieved with low gain and long integral time in basic PID oil level controllers)

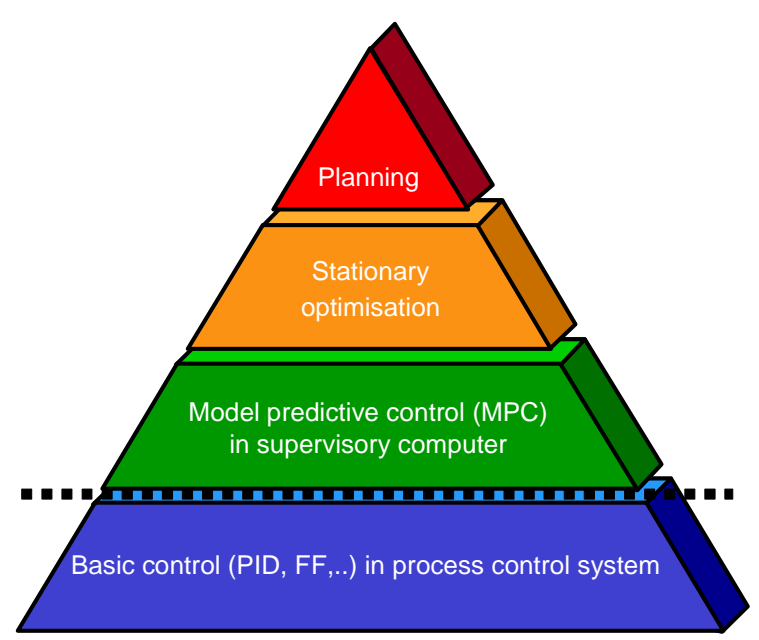

Fig. 5. Typical process control layer structure. 
The following variables are selected to achieve the goals for supervisory control with SEPTIC:

- $\quad$ Manipulated variables (MV's): controller set points for water and oil level in the separators

- Controlled variables (CV's): water and oil levels in the separators

- Measured disturbance variables (DV's): pressure at riser top for each pipeline.

These MPC applications are quite simple with two MV's, two CV's and one DV for each Tordis pipeline (A and B). It exploits the main advantages of MPC: multivariable control, feedback and feedforward control and constraint handling.

An analysis showed that a pressure drop at the riser top was a good indication for a coming water slug. Step-response models (Fig. 6) describing the relationship between changes in this pressure and the water and oil levels in the separators, were built using the Taj-Ji ID software (Zhu, 2000).

SEPTIC applies the dynamic models between the level set points and the levels as well as disturbance models (Fig. 7). If the level response differs from the expected, then SEPTIC updates the $\mathrm{CV}$ biases to counteract for this (feedback, integral action). This discrepancy may stem from imperfect models or unmeasured process disturbances. More aggressive action will take place if SEPTIC predicts that a high or low level constraint will be intersected during the prediction horizon.

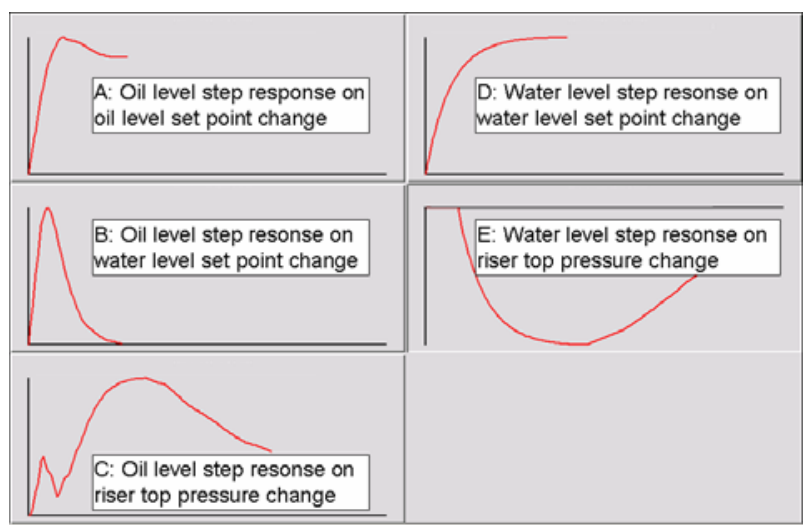

Fig. 6. Step response models for the Tordis B SEPTIC application. The two upper models (A and $\mathrm{D}$ ) show the step response of the basic PID level controllers for oil and water, respectively. The interaction between the oil level and the underlying water level is seen in the model B. An increase of the water level set point will affect the oil as well as the water level. Changes in the oil level will, however, not have an effect on the water level. The models $\mathrm{E}$ and $\mathrm{C}$ are used to predict incoming water slugs. Model E shows that a pressure drop gives a pre-warning about 1 minute before a water slug will enter the separator and give an increase in the water level, while model $\mathrm{C}$ shows that a water slug means less oil and a decrease in the oil level.
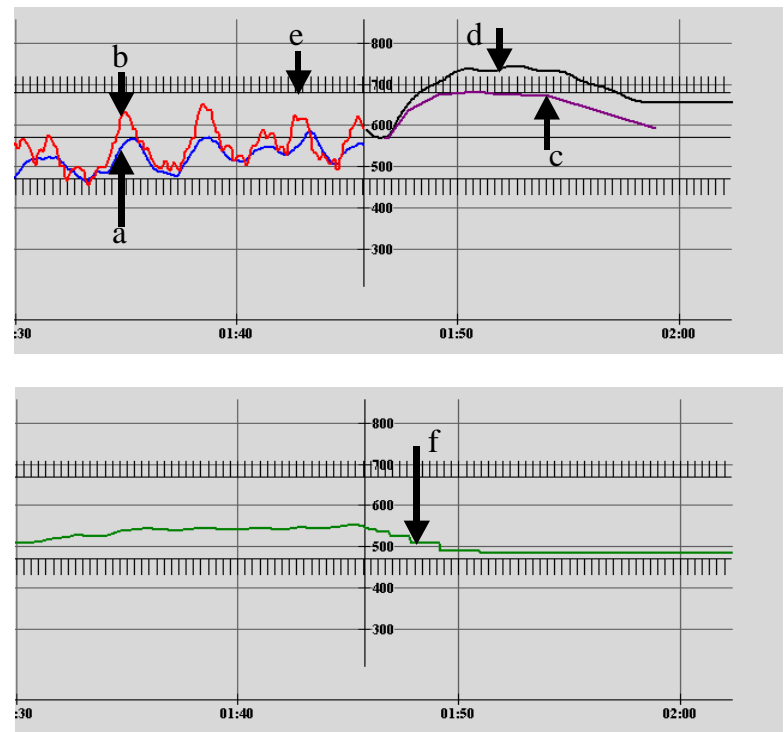

Fig. 7. The Tordis B SEPTIC application in action. The prediction horizon is to the right and the historical horizon is to the left of the vertical line in the centre of the figure. The predicted (a) and measured (b) values of the water level are shown to the left (historical), while the predicted level with (c) and without (d) active MPC is shown in the prediction horizon. It is seen here that it is expected that the upper level limit (e) will be intersected without MPC (d), but not (c) if the MPC is allowed to reduce the set point (f) as shown in the lower figure.

The Tordis SEPTIC applications have faster dynamics than the onshore applications of SEPTIC. The sampling time is 5 seconds, the prediction horizon is about 16 minutes long (200 samples) and the historical horizon (for plotting only) is about 33 minutes long (400 samples).

\section{RESULTS}

The pipeline pressure was reduced with 8 bar and resulted in a $3 \%$ increase in the oil production rate capacity. The increased production rate corresponds to a project payback time of about three weeks. A combination of active slug control using the topside choke and MPC was applied to improve the control of the receiving facilities. Riser slugging is suppressed with active slug control and production is kept stable with a constant pipeline inlet pressure. The handling of water slugging and other medium frequency variations was improved with MPC using Statoil's own tool for advanced control, SEPTIC. Level and flow variations and the number of level alarms were reduced significantly.

\section{CONCLUSION}

In this paper a control structure for both suppression and handling of slugs in multiphase oil and gas pipelines has been presented. The success of this control structure has been verified offshore at Gullfaks C for the tie-in of the Tordis subsea field, where it has been used in continuous operation since November 2003. The two slug control systems 
running have proved to have a very good slug suppression capability, which has made it possible to reduce the operating pressures and increase the production capacity of the pipelines considerably. The slug controller uses the topside choke to suppress large riser slugs, while the MPC manipulates the separator level set points to prepare for reception of flow variations such as water slugs. Start-up and operation of the pipelines as well as well-testing have also been improved, thanks to the slug control system.

\section{REFERENCES}

Courbot A. (1996). Prevention of Severe Slugging in the Dunbar 16" Multiphase Pipeline, Offshore Technology Conference, Houston, Texas, USA.

Fard, M., J.-M. Godhavn and S. I. Sagatun (2005), Modelling and Slug Control Within OLGA, submitted to SPE Journal.

Godhavn J.-M, M. P. Fard and P. H. Fuchs (2005), New Slug Control Strategies, Tuning Rules and Experimental Results, Journal of Process Control 15, pp 547-557.

Havre K., K. O. Stornes, and H. Stray (2000). Taming slug flow in pipelines, $A B B$ Review (4).

Havre K. and M. Dalsmo (2001). Active feedback control as the solution to severe slugging, SPE Annual Technical Conference and Exhibition, SPE 71540.

Hedne P. and H. Linga (1990), Suppression of Terrain Slugging with Automatic and Manual Riser Choking, ASME Winter Annual Meeting, Dallas, Texas, Nov. 1990; Printed in Advances in Gas-Liquid Flows

Henriot V., A. Courbot, E. Heitzé and L. Moyeux (1999). Simulation of process to control severe slugging: Application to the Dunbar pipeline, SPE Annual Technical Conference and Exhibition, SPE 56461.

Hollenberg J. F., S. Wolf and W. J. Meiring (1995). A Method to Suppress Severe Slugging in Flow Line Riser Systems, Oil \& and Gas Journal.

Schmidt, Z., J. P. Brill and H. D. Beggs (1979a): How to Control Slugging in Oilfield Piping, Southwestern Petroleum Short Course.

Schmidt Z., J. P. Brill and H. D. Beggs (1979b). Choking can eliminate severe pipeline slugging, Oil \& and Gas Journal, November 1979, pp 230-238.

Skofteland, G., S. Strand and K. Lohne (1998). Successful use of a Model Predictive Control system at the Statfjord A platform. IIR Conference on Offshore Separation Processes, Aberdeen, UK.

Skofteland, G. and J.-M. Godhavn (2003). Suppression of slugs in multiphase flow lines by active use of topside choke - Field experience and experimental results, 11th BHR Group Multiphase Production International Conference, San Remo, Italy, pp 527-542.

Storkaas E. and S. Skogestad (2002), Stabilization of severe slugging based on a low-dimensional nonlinear model, AIChE Annual meeting, Paper 259e, Indianapolis, USA.
Storkaas E. and S. Skogestad (2003), A lowdimensional dynamic model of severe slugging for control design and analysis, 11th BHR Group Multiphase Production International Conference, San Remo, Italy, pp. 117-133.

Strand, S. T. and J. R. Sagli (2003). MPC in Statoil - advantages with in-house technology, Symposium of Advanced Control of Chemical Processes (Adchem-2003), Hong Kong, China.

Taitel Y. and D. Barnea (1990). Two-Phase Slug Flow, Advances in heat transfer, Vol. 20.

Zhu, Y.C. (2000). Tai-Ji ID: Automatic closed-loop identification package for model based process control. IFAC Symposium on System Identification, June 2000, Santa Barbara, California, USA. 